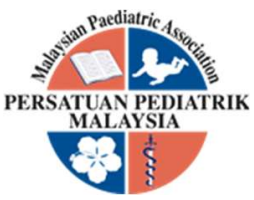

\title{
ORBITAL SWELLING: AN UNUSUAL CASE OF RELAPSED ACUTE LYMPHOBLASTIC LEUKAEMIA IN A PRESCHOOL CHILD
}

\author{
Muhammad Amiro Rasheeq Mohd Radzi ${ }^{1,2}$, Ariffin Nasiri, ${ }^{1,2}$, Ismail Shatriah ${ }^{4,2}$, Razan Hayati Zulkeflee ${ }^{3,2}$, \\ Juhara Haron ${ }^{2}$, Norsarwany Mohamad ${ }^{1,2}$
}

\begin{abstract}
Acute lymphoblastic leukaemia (ALL) is the most frequent childhood cancer. Children usually present with signs of bone marrow failure like recurrent or prolonged fever, pallor, lethargy, bleeding tendencies, bone pain and others. Occasionally they may present with sign of infiltration of leukaemic cells into other organs such as testicular and central nervous system, rarely to the periorbital or orbital region. Similarly in relapse cases, they typically presented either in bone marrow, central nervous system relapse or testicular but rarely orbital involvement. Here we report the clinical case of a five-year-old boy who developed relapsed $\mathrm{B}-\mathrm{ALL}$, presented to us with unilateral right eye swelling without other clinical findings and absence of blast cells in the peripheral blood film as well as bone marrow aspirate specimen.
\end{abstract}

Keywords: Acute Lymphoblastic Leukaemia, Relapsed, Eye Swelling

DOI: $10.51407 / \mathrm{mjpch} . v 27 i 2.139$

\section{Introduction}

Acute lymphoblastic leukaemia (ALL) is the most frequent childhood cancer diagnosed at the age of birth to 14 years [1]. They may present with viral-like illness mimicking symptoms such as fever, fatigue and pallor. Hence, it is vital to assess for other features that are more specific to ALL for example hepatomegaly, splenomegaly, lymphadenopathy, and petechial rash $[2,3]$. Testes and central nervous system are among the commonest extramedullary site for leukaemic cell infiltration [4]. Otherwise, orbital involvement as the presenting symptom for relapsed ALL is very rare, unlike those with acute myeloid leukaemia (AML) [4]. Orbital presentation may indicate a more aggressive disease, therefore early recognition plays an important role in prognostication of the disease $[5,6]$.

In this case report, we detail the clinical course of a five-year-old boy who developed unilateral right eye swelling post-completion of chemotherapy.

\author{
Received: 22 December 2020; Accepted revised \\ manuscript: 04 August 2021 \\ Published online: 03 October 2021
}

\section{Case report}

The patient presented at the age of 1 year and 9 months old with four days history of fever, facial puffiness, and abdominal distension. He had pallor, generalized lymphadenopathy and hepatosplenomegaly. The initial full blood picture showed bicytopenia with $47 \%$ circulating blast cells. The bone marrow aspirate (BMA), trephine biopsy and immunophenotyping confirmed presence of $51 \%$ blast cells with common B-ALL and an aberrant expression of CD13. His cerebrospinal fluid (CSF) analysis showed the

\footnotetext{
'Department of Paediatrics, School of Medical Sciences, 16150, Universiti Sains Malaysia, Kubang Kerian, Kelantan, Malaysia ${ }^{2}$ Hospital Universiti Sains Malaysia, 16150, Kubang Kerian, Kelantan ${ }^{3}$ Department of Haematology, School of Medical Sciences, 16150, Universiti Sains Malaysia, Kubang Kerian, Kelantan, Malaysia ${ }^{4}$ Department of Opthalmology and Visual Science, School of Medical Sciences, 16150, Universiti Sains Malaysia, Kubang Kerian, Kelantan, Malaysia

${ }^{5}$ Department of Radiology, School of Medical Sciences, 16150, Universiti Sains Malaysia, Kubang Kerian, Kelantan, Malaysia Corresponding Author:

Norsarwany Mohamad, Department of Paediatrics, School of Medical Sciences, Health Campus, Universiti Sains Malaysia, 16150 Kota Bharu, Kelantan, Malaysia Tel.: +6097473000 Email: sarwany@usm.my
} 
presence of blast cells. He was started on ALL BFM95 (moderate risk) due to elevated leukocyte count of $34.36 \times 10^{9} / \mathrm{l}$. Following the completion of the chemotherapy protocol after two and a half years, he was in remission with minimal residual disease detection level $(<0.01 \%)$.

He presented again 4 months after completed his chemotherapy regimen with a month history of frontal headache and sudden onset of right eye swelling. There were right upper eyelid swelling and proptosis of the right orbit. The symptoms persisted (Figure 1) with progression into the periorbital area. There was no retro-orbital pain, no extraocular muscle palsies, diplopia, nystagmus or chemosis. The presentation did not appear consistent with an infectious aetiology.
After a few days in the ward, he developed status epilepticus requiring ventilation for cerebral protection. A computed tomography (CT) brain and magnetic resonance imaging (MRI) brain showed enhanced right intraconal mass measured about $2.6 \times 1.5 \times 2.4 \mathrm{~cm}$ (anteroposterior, width and cranial caudal) respectively with a deviation of the right optic nerve medially and infiltrated into the right cavernous sinus (Figure 2).

Repeated bone marrow aspirate and immunophenotyping a month later demonstrated evidence of early relapse of B-ALL. Thus, he was treated as relapsed B-ALL and started with (Standard 2) REZ BFM chemotherapy protocol.

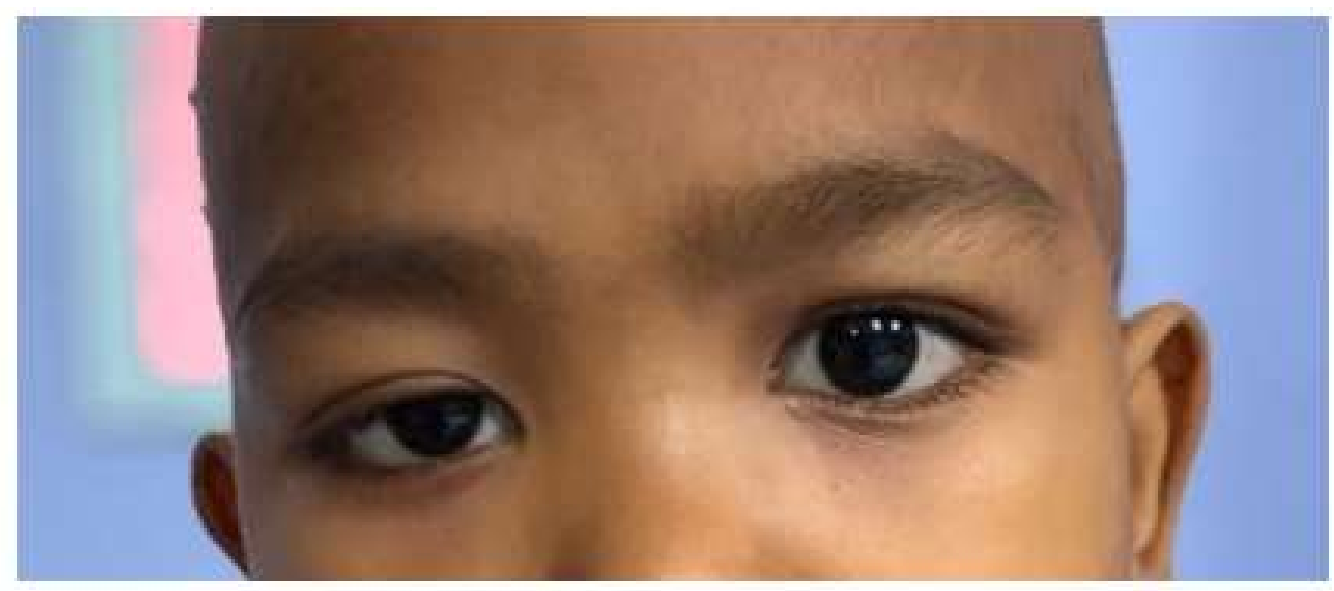

Figure 1. The picture showing swelling over right eye and proptosis.

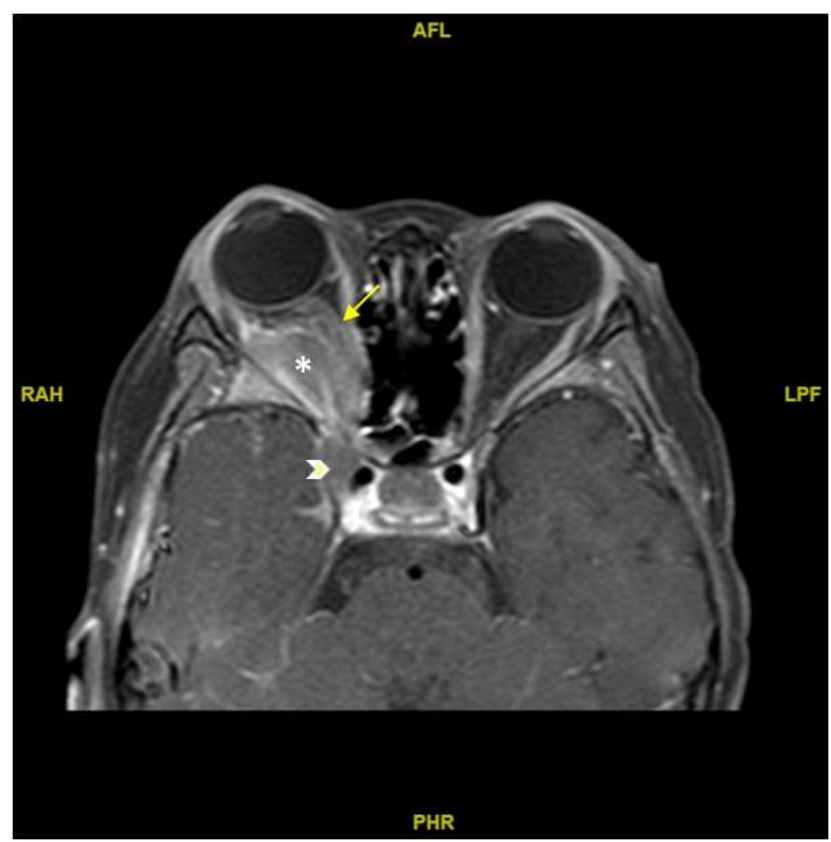

Figure 2. Contrast-enhanced axial T1W MRI orbit shows right intraconal mass (*) displacing the optic nerve medially (arrow). There is extension of the mass into the cavernous sinus (arrow head). 


\section{Discussion}

Several case reports have shown patients that have similar presentation to our patients $[7,8]$. Both reported patients presented with an isolated periorbital swelling without local signs of infection. They were initially treated for infectious aetiologies until the bone marrow biopsy confirmed the diagnosis of ALL. The difference was these patients had orbital findings at the early presentation of the disease while unfortunately in our patient, the orbital symptoms were the early feature of the relapsed ALL.

In addition to leukaemia, many other pathologies that need to be excluded when the patient presents with unilateral proptosis or eye swelling. It can be due to solid tumour, infection or vascular malformations. Otherwise, it also can be divided into the osseous and non-osseous lesion [2]. Table 1 simplified the causes of unilateral eye swelling in children.

Table 1: Common causes of unilateral eye swelling in children [9-11]

\begin{tabular}{|c|c|}
\hline Osseous & Non-osseous lesion \\
\hline $\begin{array}{l}\text { Dermoid cyst is the } \\
\text { most common } \\
\text { paediatric osseous } \\
\text { tumour, fibrous } \\
\text { dysplasia, juvenile } \\
\text { ossifying fibroma, } \\
\text { osteosarcoma, } \\
\text { Langerhans cell } \\
\text { histiocytosis and bony } \\
\text { metastases from } \\
\text { neuroblastoma }\end{array}$ & $\begin{array}{l}\text { Rhabdomyosarcoma, } \\
\text { vascular origin } \\
\text { (capillary } \\
\text { haemangioma, } \\
\text { venous-lymphatic } \\
\text { malformations) as well } \\
\text { as infantile } \\
\text { fibromatosis and } \\
\text { nerve sheath tumours } \\
\text { (optic nerve glioma) }\end{array}$ \\
\hline
\end{tabular}

These showed to us that the presentation of unilateral periorbital swelling in a patient with history of leukaemia warrants a careful assessment in order not to miss important differential diagnosis especially early relapse. The dilemma occurs when bone marrow and CSF did not support relapse finding. The decision to perform an orbital biopsy does not come without a risk.

\section{Conclusion}

We described the clinical course of a five-year-old boy who presented with unilateral periorbital swelling as his first relapse symptoms of ALL. This is not a typical presentation of relapse leukaemia. Thus, this case brings enlightenment that periorbital oedema or swelling or proptosis must always be approached with thorough and broad differential as serious underlying causes may be present.

\section{Conflicts of interest}

I do not believe that there is a conflict of interest that could potentially be construed to affect the material contained in the manuscript that is being submitted to the journal.

\section{References}

[1] Taylor CW, Taylor RE, Kinsey SE. Leukemic infiltration of the Orbit: Report of three cases and literature review. Pediatric Hematology and Oncology. 2005; 22(5): 415-22.

[2] Ward E, DeSantis C, Robbins A, Kohler B, Jemal $A$. Childhood and adolescent cancer statistics. CA: a cancer journal for clinicians. 2014. 2014; 64(2): 83-103.

[3] Kiratli H, Bilgiç S, Emeç S. Simultaneous conjunctival, uveal, and orbital involvement as the initial sign of acute lymphoblastic leukemia. Japanese Journal of Ophthalmology. 2007; 51(2): 139-41.

[4] Hossain IT, Moosajee M, Abou-Rayyah Y, Pavasovic V. Orbital mass secondary to infantile acute lymphoblastic leukaemia. Case Reports. 2016; 2016: bcr2016214872.

[5] Ramamoorthy J, Jain R, Trehan A, Saxena AK, Ahluwalia J. Orbital mass in a child with acute lymphoblastic leukemia: a case report and review of the literature. Journal of Pediatric Hematology/Oncology. 2016 Nov 1;38(8): 646-8.

[6] Thakker MM, Rubin PA, Chang E. Pre-B-cell acute lymphoblastic leukemia presenting as an orbital mass in an 8-month-old. Ophthalmology. 2006 Feb 1;113(2): 343-6. 
[7] Ahuja R, Azar NF. Orbital dermoids in children. In Seminars in Ophthalmology. 2006 Jan 1 (Vol. 21, No. 3, pp. 207-211). Taylor \& Francis.

[8] Clarke RT, Van den Bruel A, Bankhead C, Mitchell CD, Phillips B, Thompson MJ. Clinical presentation of childhood leukaemia: a systematic review and meta-analysis. Archives of Disease in Childhood. 2016 Oct 1;101(10): 894-901.

[9] Reddy SC, Jackson N, Menon BS. Ocular involvement in leukemia-a study of 288 cases. Ophthalmologica. 2003; 217(6): 441-5.

[10] Chaudhry SR, Kreis AJ, Underhill HC, Madge SN. Orbital mass secondary to acute lymphoblastic leukaemia in a child: a rare presentation. Orbit. $2014 \mathrm{Dec}$ 1;33(6): 421-3.

[11] Stein AP, Norris RE, Shah JR. Pediatric acute lymphoblastic leukemia presenting with periorbital edema. Otolaryngology Case Reports. 2018 Nov 1;9: 11-4. 